\title{
An Interpretation of an Interactive Model: Urban Culture Coordinating Rural Culture or Rural Culture Combining Urban Culture
}

\author{
Gu Jijian \\ Chongqing Communications Vocational College, Jiangjin, Chongqing 402247 \\ E-mail: gumuran2006@126.com
}

\begin{abstract}
The division of cultures between urban and rural areas is a concept that explores the inevitability of cultural development. The relationship between the two, namely whether one co-ordinates the other or the two intersect, merge and interact in the process of co-ordination is the question that we explore. It is also the core issue of the division of cultural urban and rural areas.
\end{abstract}

Keywords: culture, urban-rural coordination, interactive mode

\section{INTRODUCTION}

Urban-rural integration is the development of cultural integration from a cultural perspective. The relationship between cultural integration involves the urban-rural distinction of culture. Maybe culture is artificially distinguished into urban culture and rural culture, but according to the consumption status of regions and cultures, the cultural system can be divided by the integration trend of urban and rural areas now and in the future, especially culture is treated as a high-level productive force in the cultural industrialization process. It is a concept that cannot be ignored or confused. Therefore, it is necessary to explain the process and results of inevitable conflicts and fusions of cultures in the urban and rural overall development from the "strength" of urban culture and the "ecological type" of rural culture (the concepts or meanings of "strength" and "ecological type" are explored in the main content behind). It is a process of constructing and improving an interactive model.

\section{The "dominance" of urban culture}

The "dominance" of urban culture is interpreted as a guide to popular consciousness and a push for productive force liberation, or to be clearly in a superior position when opposing rural cultures, whether it is public recognition or politics, it is more or less driven by the stigma of "status" inequality. Although this is not a dominant problem or has not reached the point where we intentionally correct it, its existence cannot be denied. (1) With the guidance of popular consciousness, political culture obviously has all the connotations of urban culture, and urban culture can feel its guidance and "domination" of society from all corners of society. Including the consumption trend led by consumer advertising, the flood of clothing, the spread of fashion, the settings of accommodation, etc., the guides covering food, clothing, and use are almost inclusively originated from the cultural atmosphere of the city. Rural cultures can hardly affect public ideology, nor promote social psychology proceeding on the path of rural culture, which indicates that urban culture in a dominant position to a certain extent can restrict the thinking of the public and lead the social consciousness to develop in the direction of urban culture.(2)The promotion of productive force liberation, the world's generally recognized viewpoints and real situations can explain that the cities are a symbol of modern civilization, the center of modern social development, and the main axis of social productive force liberation. Although the villages have a status and role that cannot be ignored, urban culture is the main component of urban productive forces. At this point, the history of rural culture is incomparable. In other words, to a significant degree of cultural liberation of productive forces, urban culture is far away from the public. In front of society, therefore, in this sense, the history of urban culture is strong.

But culture is a system after all, it cannot or is difficult to be divided. Even if there is such a point in real life that it can be separated unintentionally or unintentionally, it is not the difference between elegance and popularity, fashion and mediocrity, avant-garde and outdated which are just the appearance of culture. The real culture systems can be coupled together, interact, and form a benign operating model, which is based on that rural culture has value and space of its existence, and urban culture can respond to it. Therefore, we have to say that the implicit "ecological type" of rural culture supports the cultural system.

\section{The "ecological type" of rural culture}

The "ecological type" of the rural culture here can be explained from three aspects namely non-dominant, survival status, and consciousness of benefiting farmers, so as to be different from urban culture. (1) Non-dominant means that since the ancient times, the culture of the villages has always formed a trend of making friends with each other, helping each other, supporting each other with disease, working at sunrise, resting at sunset, and conforming to nature. Compared with the indestructible tendency of the materialism of urban culture, it is obviously in an "obscure" situation, even if the corresponding release of productive forces is obviously enough without obvious supporting materials. However, it can't be denied that village intangible cultural heritages represented by the Tongliang dragon dance, the folk songs 
of the Miao nationality in Anzi, the Chuanjiang labor songs, the Liangshan lantern opera, the hand-waving dance of the Tujia nationality in Youyang, the Sichuan face-changing opera, the Sichuan bamboo harp, the folk songs of the Tujia nationality, the Xiushan lanterns, the Liangping wooden new-year paintings, and the Sichuan embroidery, etc. have made great contribution to rural development, continued the essence of rural culture for thousands of years, and accumulated agricultural civilization which is the cornerstone of the development of rural productive forces.(2)The reason why the living state of rural culture is a manifestation of "ecological type" is that the mother state of all cultures is rural culture, and the more ancient these village cultures are, the more original the ecology that preserves the most complete human culture. Only then can we discover the context of cultural development and the ravages of cultural development, especially urban culture with obvious material desires. This is the most important issue in the process of urban-rural coordination. The urban culture could draw some lessons from the rural culture. (3) Rural culture's consciousness of benefiting farmers. It is a difficult term to understand or easy to misunderstand. In fact, as Emmanuel Le Roy Ladurie pointed out, the concept of fate is a kind of "old and normal thought of peasants" in a society lack of economical development and choices. The concept of "destiny" allows people to accept existing results. Popular sayings like "admit that one's misfortune is predetermined" all play this role. However, it does not lead to absolute negativeness and despair. At any time, the power of "luck" is a vague expectation that motivates farmers. When a poor peasant says that he is "unlucky", his subtext is that "every dog has his day", "changeable in prosperity and capricious in rise and fall", and "lands are transferred to three owners in a hundred years" which all expressed the changes of results due to the reversal of fate. This kind of poor-to-rich transition that often takes one generation as a cycle is likely to comfort the modern rural people's minds, and more traditional farmers who want to complete the natural transmission from their predecessors to their descendants are the goal of life value, which is also a kind of invisible welfare to the society, namely social stability.

The reality is that there are a lot of discord between the two sub-cultural states of this cultural system, which is most obvious in the process of urban-rural coordination. The traditional thinking and contradiction of the rural people will surely be stable in the city. Conflicts have arisen in the country's statutes for cultural leaders or new officials. Rural urbanization is more focused on rural-urban connections and interactions, rural management, lifestyles and thinking which gradually become closer to the city and tend to be the same, but it is difficult for rural culture and urban culture to merge with each other. Although rural urbanization is an important idea for China's rural development, in the report and long-term planning of the National People's Congress of the CPC Central Committee and the State Council, rural urbanization is an important content, but the process of urbanization, namely the process of urban coordination of rural areas, a large number of sub-cultural systems are not integrated, which is the root cause of urban-rural coordination difficult to implement, therefore we have to study the relationship between the two cultural subsystems.

\section{THE INTERACTIVE MODE OF URBANCULTURE AND RURAL CULTURE}

From the perspective of the above-mentioned subsystems of the cultural system, each has its own strengths and advantages, and only the two are an organic whole to form a complete cultural system and the entire composition of Chinese civilization. The problem of farmers and cities, specifically the urban-rural coordination in the process of civil society construction is not essentially urban coordination of rural areas and rural areas becoming cities, but urban culture and rural culture constitute different levels of the cultural system. Interaction with each other, that is, to complete the trial process of urban-rural coordination, the integration or integration of urban culture and rural culture must be achieved. Then, is it the urban cultural integration of rural culture or the integration of rural culture with urban culture to form a cultural interaction model? What exactly is it? Our research found: (1)Based on the tradition of agricultural production, the rural culture keeps changing, and believes in all things and rules. It has won the essence of the "harmony between the heaven and men". For the sake of being valuable and respecting the impact of righteousness and benefit, thinking about things and seeking peace, the atmosphere, the folk customs, the emotions, and the concept of life are all simple, the communication style is good, and the neighborhood relations are harmonious. However, it can overcome the utilitarianism and benefits of urban culture. The real interest tendency and the complex interpersonal relationship can also provide a reference for its self-reflection in the emphasis on manpower, showing the humanity's domination and conquest of natural predation, or the combination of rural culture and urban culture. (2) Traditional rural culture is generally disadvantaged in the face of urban culture and is often shocked by urban culture and then transformed or abandoned. These phenomena are not only the existence of rural reality in China, but also to some extent scorned and disdained by urban culture. It is also important to consider the issue from the perspective of rural culture, take the initiative to lean down and talk to the countryside on an equal footing. The collision and confrontation between the two can build cultural harmony, and the perfect operation of the urban-rural interaction model.

\section{CONCLUSION}

In short, the process of urban-rural coordination should be a process in which urban culture and rural culture interact with each other and progress together. The process of urban culture and rural culture contacting and merging makes the more sympathetic and modern urban culture coexist and co-prosper. It is also the process of urban and rural cultural integration. Urban and rural dynamic cultures will dissipate, and there will be rebirth, collisions, conflicts, exchanges, and integration, each taking what is needed, each eliminating its disadvantages, bridging the gap, and forming complementarities (Li Huizhao, 2007). The entry of rural residents into the city has continuously strengthened the integration between urban and rural cultures, and has caused urban cultures characterized by modern industrial civilization and rural cultures represented by traditional rural civilizations to begin their collision, friction, and blending, to varying degrees. The integration of urban and rural cultures has been enriched 


\section{REFERENCES}

culture in and rural cultures have affected the economic development of the region. To gauge its gains and losses, it is necessary to refer to the ethnic opinions of this culture and life, it is best not to rise to the will of the country without consulting the regional ethnic groups, which often naturally makes culture obey the will of the country in an involuntary and uneconomic way. "In May 2007, in order to change the image of the city and expand investment, a construction site took part in the construction of a part of the Yangshao cultural site 6,000 years ago during the holidays but destroyed rare burial caskets and precious relics such as Tao Ding" (Feng Yucai, 2008). It needs to be raised at the height of the national will, especially for the cultural events in China, to leave a little virgin land for urban and rural culture to improve the social and ecological environment of urban and rural cultural heritage existence. In short, "the urban culture characterized by modern industrial civilization and the rural culture represented by traditional rural civilization have begun to contact, collide and merge, result in the conflicts and integration between urban and rural culture" [3]. The tearing of the two presents a one-sided approach. Urban culture clearly has an advantage, and rural culture is relatively unfamiliar. The current integration of the two cannot yet achieve an interactive path. It requires the guidance of social development and cultural institutions. In the future, it will be able to integrate and advance to a certain extent and within a certain range, and achieve a new height in culture. The use of new media resources to open the industrial chain and bring out the role of urban and rural culture.

\section{ACKNOWLEDGMENT}

First of all, I would like to express my gratitude to all those who helped me during the writing of this thesis. I gratefully acknowledge the help of my supervisor, who has offered me valuable suggestions in the academic studies. In the preparation of this thesis, she has spent much time reading through each draft and provided me with inspiring advice. Without her patient instruction, insightful criticism and expert guidance, the completion of this thesis would not have been possible.

Secondly, I also owe a special debt of gratitude to all the professors in Foreign Languages Institute, from whose devoted teaching and enlightening lectures I have benefited a lot and academically prepared for the thesis.

Lastly, I should finally like to express my gratitude to my beloved parents who have always been helping me out of difficulties and supporting without a word of complaint.

\section{ABOUT THE AUTHOR}

Gu Jijian (1980.8-) male, Han, Shandong, Ph.D., professor of Chongqing Jiaotong Vocational College, master tutor, mainly engaged in higher education and cultural industry research

Phone: 15826150008 E-mail: gumuran2006@126.com

Mailing address: No. 555 Xiangfu Avenue, Shuangfu

Street, Jiangjin District, Chongqing

Zip code: 402247
[1] Li Huizhao. The Collision and Integration of Urban and Rural Culture-Analysis of the TV series "New Marriage Times". Movie Review, 2007.10, p32.

[2] Feng Xicai. Cultural Heritage and Wealth of Future Generations. China Supervision, 2008.3, p60.

[3] HeYanfei. The Conflict and Integration of Urban Culture and Rural Culture. Journal of Theory, 2016.1, p147.

[4] WuMing. Historical Significance, Practical Significance and Future Significance of Rural Culture. https://www.sohu.com/a/328013610_678825,2019-07-19. 